OPEN ACCESS

Edited by:

Fei Meng,

Swinburne University of Technology,

Australia

Reviewed by:

Zhongqiong Zhang,

Northwest Institute of ECO-

Environment and Resources (CAS),

China

Yin Song,

Zhongyuan University of Technology,

China

*Correspondence:

Ran An

anran@wust.edu.cn

Specialty section:

This article was submitted to

Geohazards and Georisks,

a section of the journal

Frontiers in Earth Science

Received: 08 September 2021

Accepted: 27 September 2021

Published: 13 October 2021

Citation:

An R, Zhang X, Kong L, Gong J and Lei $X$ (2021) Artificial Ground Freezing

Impact on Shear Strength and Microstructure of Granite Residual Soil Under an Extremely Low Temperature.

Front. Earth Sci. 9:772459.

doi: 10.3389/feart.2021.772459

\section{Artificial Ground Freezing Impact on Shear Strength and Microstructure of Granite Residual Soil Under an Extremely Low Temperature}

\author{
Ran $\mathrm{An}^{1 *}$, Xianwei Zhang ${ }^{2,3}$, Lingwei Kong ${ }^{2,3}$, Jianwu Gong ${ }^{1}$ and Xuewen Lei ${ }^{4}$ \\ ${ }^{1}$ Wuhan University of Science and Technology, Wuhan, China, ${ }^{2}$ Chinese Academy of Sciences (CAS), Beijing, China, ${ }^{3}$ Institute of \\ Rock and Soil Mechanics (CAS), Wuhan, China, ${ }^{4}$ School of Health Sciences, Wuhan University, Wuhan, China
}

The Artificial Ground Freezing (AGF) method, which is widely used in tunnel excavations, significantly affects the properties of geotechnical materials in frozen walls under extremely low temperatures. In order to simulate the AGF process, the freezing treatment with a temperature of $-30^{\circ} \mathrm{C}$ and thawing treatment temperature of $25^{\circ} \mathrm{C}$ were performed on natural specimens of granite residual soil (GRS). Subsequently, triaxial (TRX) tests were conducted to evaluate mechanical properties and Nuclear Magnetic Resonance Image (NMRI) tests were applied to detect pore distributions of GRS. To clarify variations of microstructure after freezing-thawing, the relaxation time $\left(T_{2}\right)$ distribution curves and $T_{2^{-}}$ weighted images from NMRI results were thoroughly analyzed from the perspective of quantization and visualization. Results show that the shear strength as well as the cohesion of GRS are reduced sharply by the AGF process, while the internal friction angle decreases gently. The pore size distribution (PSD) converted from the $T_{2}$ curve is constituted of two different peaks, corresponding to micro-pores with diameters from 0.1 to $10 \mu \mathrm{m}$ and macro-pores with diameters from 10 to $1,000 \mu \mathrm{m}$. Under the AGF impact, the expansion in macro-pores and shrinkage in micro-pores simultaneously exist in the specimen, which was verified from a visualized perspective by $T_{2}$-weighted images. The frost heaving damage on shear strength is attributed to the microstructural disturbance caused by the presence of large-scale pores and uneven deformations in GRS, which is subjected to the AGF impact under an extremely low temperature.

Keywords: artificial ground freezing method, granite residual soil, frost heaving damage, pore size distribution, shear strength

\section{INTRODUCTION}

For decades, a growing number of metro engineering projects have been under construction in large and medium-sized cities in China, as a result of rapid developments of urbanizations (Fang et al., 2011; Chen et al., 2015; Liu et al., 2021). Meanwhile, urban environments and geotechnical properties have been inevitably influenced by subway tunnel excavations at a varying degree during construction and operation periods (Fu et al., 2014). Currently, the artificial ground freezing (AGF) method is widely used in tunnel excavations due to its advantages of broad applicability, high strength performance, seepage prevention, and environmental protections (Lackner et al., 2008; Liu et al., 2017). Although the AGF method has great advantages, the frost heaving damage and 


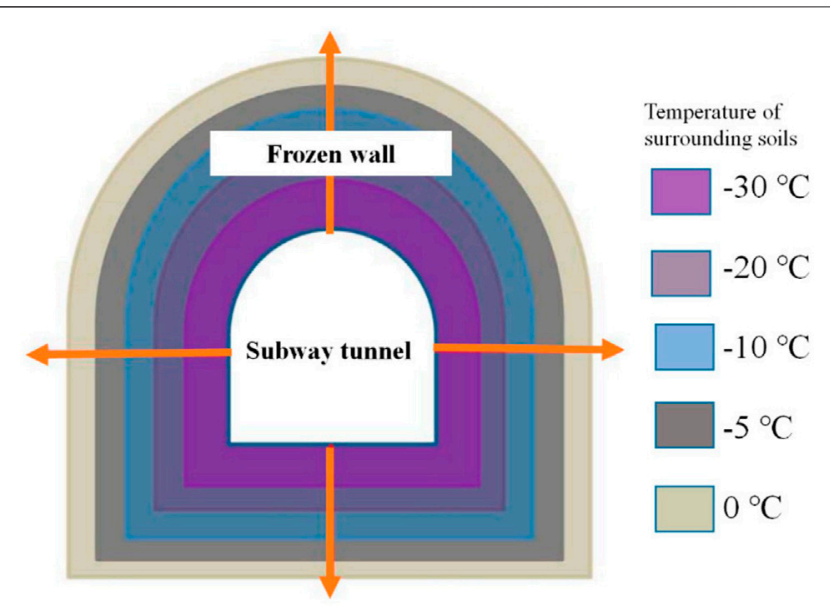

FIGURE 1 | Diagram of the AFG method applied to tunnel constructions.

thaw-induced deformations of geotechnical materials during construction adversely affects the stability of underground structures (Vitel et al., 2015). As the AGF method in tunnel constructions is used more frequently, it is evident that our knowledge about the mechanical behaviors and microstructure of soils is insufficient at this stage (Pimentel et al., 2012).

Granite residual soil (GRS), which is considered as a kind of problematic soil, is extensively distributed in the southeast areas of China (An et al., 2019). The GRS that contain montmorillonite, illite, and other hydrophilic minerals are easily affected by the environmental changes they experience (Toll and Ong 2015). Presently in China, the distributed regions of granitic regolith generally create engineering problems for infrastructure constructions (He et al., 2020). Due to inferior properties, such as high permeability, high compressibility, low strength, and easily-disturbed characteristics of GRS, the AGF method serves as an important constructing technique of metro tunnels and cross passages in the formations (Fonseca et al., 2006). Under the influence of freezing-thawing $(\mathrm{F}-\mathrm{T})$ process, the mechanical characteristics of soils are severely degraded by frost heave and cracking propagation (Konrad and Morgenstern, 1980). Therefore, the structural damage of GRS caused by F-T process induces potential dangers to the safe operation of subway tunnels, increasing the probability of losing stability control during excavations.

A substantial amount of findings in the field of frost heave on soils have been made in the past decades, particularly in the frozen earth regions (Black and Tice 1989; Bronfenbrener and Bronfenbrener, 2010; Cécile et al., 2016; Bai et al., 2018). During AGF constructions, the frost heaving effect kept the soils around tunnel pipes at negative temperatures (Zhou and Tang 2015). Generally, the temperature of the interfaces between tunnel pipes and geomaterials can reach an extremely low value of $-30^{\circ} \mathrm{C}$ ( Han et al., 2016). In addition, an increasing distance between the soil and pipes results in a rise in the temperature of soil, as presented in Figure 1. Recently, the impacts of AGF method on soils in frozen walls has become of increasing concern. Pichler and Lackner (2003) concluded that the micromechanical performance of soils was reduced remarkably after performing artificial freezing method, resulting in uneven deformations of the ground under dynamic loads. Cui and Zhang (2015) found that the pore structure in geomaterials exhibited uneven expansions after freezing-thawing. An et al. (2020) found the microstructure in residual soil showed a significant variation after the AGF treatment by performing NMR and SEM tests. It is generally believed that the F-T process affects not only physical characteristics such as porosity, dry density, and hydraulic conductivity, but also mechanical behaviors, such as the stressstrain relation, elastic modulus, and shear strength parameters of soils (Shoop and Bigl, 1997; Lai et al., 2010; Tian et al., 2018). Additionally, it has been well-documented that extremely low temperatures applied to soils significantly affects their microstructural characteristics (Pichler et al., 2003; Zhou and Tang 2018). However, there have been rare reports of correlations between mechanical and microstructural parameters of GRS. Even though some researchers have recently become aware of microstructural effects on mechanical properties, their concerns mostly focused on natural frozen soil, instead of soils in artificially frozen walls.

Over the past decades, non-destructive detecting methods, such as Nuclear Magnetic Resonance (NMR) and Computed Tomography (CT), have become increasingly prevalent to analyze the pore distributions in rocks and soils (Kong et al., 2017; Li et al., 2020). The NMRI technique offers an effective and reliable method to identify the microstructure in a tested material from a visual and quantitative perspective (An et al., 2020b). The NMRI scan also provides a rapid and convenient testing procedure which saves measuring time for investigating the pore-water distributions during the freezing process (Nakashima et al., 2011). Acknowledging the most functional potential of NMRI technique in measuring pore water in specimens, a set of studies have been performed on soils affected by the F-T damage (Watanabe and Wake 2009; Kong et al., 2020). Nevertheless, the relationship between macroscopic mechanical behavior and microstructure of GRS requires further exploration.

In this paper, the shear strength and pore distributions of granite residual soil under the AGF process has been focused on. In order to simulate the environmental impact of AGF construction on actual soils, undisturbed specimens of GRS were frozen at a negative temperature of $-30^{\circ} \mathrm{C}$ and then thawed at $25^{\circ} \mathrm{C}$. A set of triaxial loading tests with different confining pressures and NMRI scanning were performed to study mechanical and microstructural properties of GRS. This study contributes to the cognization of geotechnical problems involving the AGF method in tunnel constructions.

\section{MATERIALS AND METHODS}

\section{Materials}

The material studied in this paper was undisturbed GRS collected from a natural slope located in Xiamen, Southeast China. The physical properties, including the dry density $\rho_{d}$, moisture content $w$, specific gravity $G_{s}$, hydraulic coefficient $K$, and 
TABLE 1 | Physical and mineralogic properties of GRS.

\begin{tabular}{|c|c|c|c|c|c|c|c|c|c|c|}
\hline \multirow[t]{2}{*}{$\rho_{d} / \mathbf{g} \cdot \mathbf{c m}^{-3}$} & \multirow[t]{2}{*}{$W / \%$} & \multirow[t]{2}{*}{$K / \mathrm{cm} \cdot \mathrm{s}^{-1}$} & \multirow[t]{2}{*}{ Void ratio } & \multirow[t]{2}{*}{$G_{s}$} & \multicolumn{2}{|c|}{ Atterberg limits } & \multicolumn{4}{|c|}{ Mineral composition/\% } \\
\hline & & & & & $w_{\mathrm{L}}$ & $w_{p}$ & kaolinite & illite & quartz & hematite \\
\hline 1.37 & 26.03 & $1.15 \times 10^{-7}$ & 0.63 & 2.71 & 65.6 & 25.9 & 38.5 & 5.2 & 53.6 & 2.5 \\
\hline
\end{tabular}

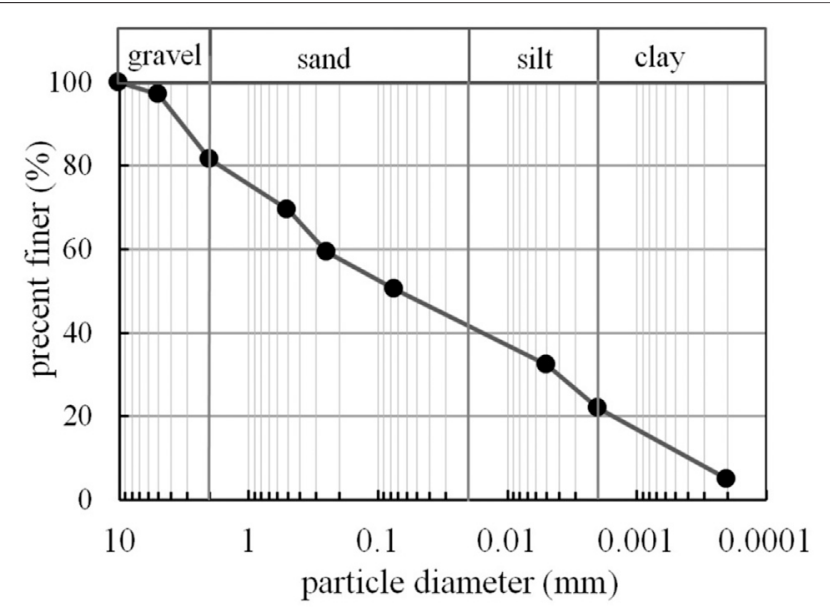

FIGURE 2 | The grain size distribution of GRS.

Atterberg limit $\left(I_{1}\right.$ and $\left.I_{\mathrm{p}}\right)$, were tested by referring to the standard GB/T 50123 (National Standard for the People's Republic of China, 1999). The mineral composition was quantitatively acquired from XRD tests by referring to the "ASTM D49262015." Basic physical parameters and the mineral composition of GRS are summarized in Table 1. The grain size distribution of GRS was measured by referring to ASTM D422-63 (2002). As presented in Figure 2, the grain distribution curve of GRS shows that fine and coarse particles both have a high proportion while intermediate-size particles have a low proportion, which is the most prominent fabric characteristic of granite residual soils.

\section{Sample Preparation}

The undisturbed specimens of GRS were collected by using the exploratory trench sampling technique at the surface of an excavation slope. Firstly, the cubic soil blocks $(30 \mathrm{~cm} \times 30 \mathrm{~cm}$ $\times 30 \mathrm{~cm}$ ) were carefully cut in the sampling field. Then, plastic films were wrapped on the surface of the soil blocks and packed into the wooden boxes which were filled with foamed materials. Eventually, the wooden boxes were fixed and transported to the laboratory. The cylinder columns with a diameter of $50 \mathrm{~mm}$ and a height of $100 \mathrm{~mm}$ were elaborately prepared from cubic blocks of soil. In order to simulate the freezing-thawing process in AGF method by laboratory tests, the prepared specimens of GRS were frozen up to a negative temperature of $-30^{\circ} \mathrm{C}$ and kept cool for $48 \mathrm{~h}$ in a programmable cryogenic freezer. Subsequently, these specimens were defrosted at room temperature of $25^{\circ} \mathrm{C}$ for $24 \mathrm{~h}$ and fully saturated by using a vacuum saturation device for $72 \mathrm{~h}$.
After the process of freezing and thawing, these samples were placed carefully in the constant temperature chamber.

\section{Test Methods}

1) Triaxial loading tests

The shear strength and stress-strain curves of GRS were measured by a set of triaxial loading tests under consolidatedundrained (CU) states, by referring to ASTM D4767-11. Standard cylinder specimens with a diameter of $50 \mathrm{~mm}$ and a height of $100 \mathrm{~mm}$ were coated with a rubber film and placed in the pressure chamber for backpressure saturations. Then, the saturated specimens were subjected to confining pressures of 100, 200, and $300 \mathrm{kPa}$. Finally, the shear process was started with the displacement increasing rate set as $0.015 \mathrm{~mm} / \mathrm{min}$. During the test, the shear process was stopped when the axial strain reached nearly $20 \%$.

\section{2) Nuclear Magnetic Resonance Image (NMRI) scans}

Before the NMRI tests, the specimen was vacuumed and then saturated by distilled water for $24 \mathrm{~h}$ to remove the air in pores to ensure a fully saturated state. The AniMR-150 NMR imaging system was applied to obtain the relaxation time $T_{2}$ spectrums and pseudo-color images of pore water through Carr Purcell Meiboom-Gill (CPMG) sequence. To generate a uniform and stable magnetic field, the testing temperature of the device was controlled to be about $25^{\circ} \mathrm{C}$. Each NMRI test takes about $30 \mathrm{~min}$ for scanning. The amplitude of NMR signal intensity $\left(\mathrm{T}_{2}\right)$ indicates the present protons in pore water and provides information of pore distributions. After the $\mathrm{T}_{2}$ distribution curves which provided information of pore distributions were obtained, the pseudo-color images of pore water in specimens were captured by the imaging function pf NMRI system.

\section{RESULTS AND ANALYSIS}

\section{Stress-Strain Behavior and Shear Strength}

The deviatoric stress versus axial strain curves of GRS before and after F-T process were measured by triaxial loading tests, as illustrated in Figure 3. It is evident that the stress-strain curves of undisturbed specimens of GRS under different confining pressures exhibit a strain-softening feature. Under the consolidation-undrainage condition, the deviatoric stress of soils increases rapidly when the axial strain reached $5 \%$. Then, the stress descended after reaching the peak stress (see in Figure 3A). For soil columns under the cooling temperature 


\section{A}

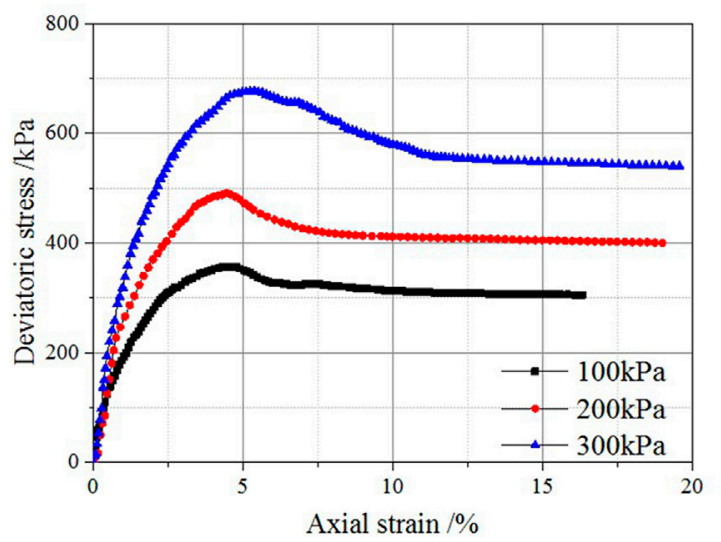

B

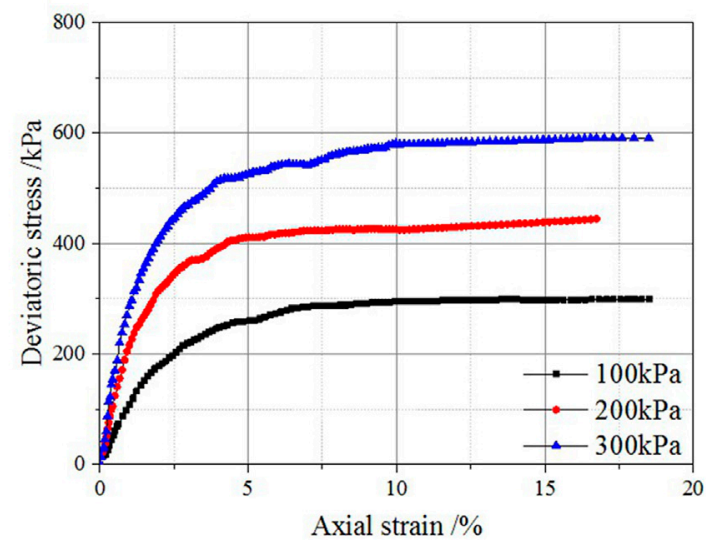

FIGURE 3 | Stress-strain curves at different confining pressures: (A) original specimens; (B) F-T specimens.

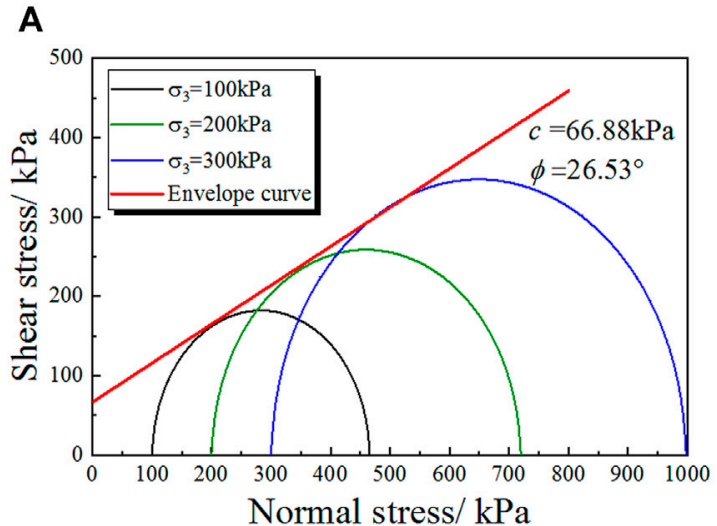

A

Normal stress/ $\mathrm{kPa}$

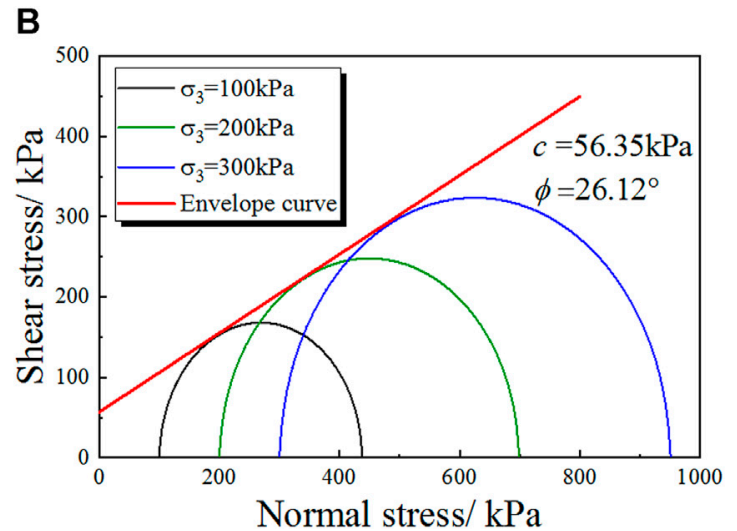

B

B) F-T specimens.
FIGURE 4 | Mohr-Coulomb failure envelope curves: (A) original specimens; (B)

of $-30^{\circ} \mathrm{C}$, the deviatoric stress rose at first and remained stable afterwards as the axial strain increases, which is characterized as a strain-hardening type (see in Figure 3B). Besides, the soil columns exhibit more brittle behavior at different confining pressures and great reductions in peak stress after freezingthawing. This phenomenon is attributed to the pressure caused by ice lens formation increasing the friability of GRS, leading to a reduction of peak stress when large deformation occurs to the specimen (He et al., 2020).

Further, the stress-strain curves of GRS before and after freezing-thawing both increase with the increasement of confining pressures, as a result of an enhancement in the elastic modulus. The relationship between the axial stress $\sigma_{1}$ and confining pressure $\sigma_{3}$ from TRX results can be interpreted according to the Mohr-Coulomb criterion (Zhang et al., 2017):

$$
\sigma_{1}=\frac{2 c \cdot \cos \varphi}{1-\sin \varphi}+\frac{1+\sin \varphi}{1-\sin \varphi} \sigma_{3},
$$

Where, $c$ denotes the cohesion $(\mathrm{kPa})$ and $\varphi$ denotes the internal friction angle $\left({ }^{\circ}\right)$.
The failure envelopes from the triaxial results are given in Figure 4. The linear relationship between the normal stress and shear strength is easy to be observed for the original and F-T specimens of GRS. After the F-T process, the envelope curves exhibit a decreasing trend along the shear stress axis, as well as the slope of the linear function (He et al., 2020). The shear parameters (cohesion $c$ and internal friction angle $\varphi$ ) of GRS before and after F-T process are obtained by the More-Coulomb criterion, as Figure 5 illustrated. Through calculating, the cohesion of GRS is reduced by about $15.7 \%$ while the internal friction angle is only reduced about $1.5 \%$. It is easily recognizable that the decreasing extent of cohesion of GRS is much higher than that of internal friction angle due to AGF effects. This phenomenon can be ascribed to the cracking behavior of GRS due to negative temperatures that mainly weaken the original cohesive force of clay aggregates rather than the friction force between the grains (Zeng et al., 2018).

\section{Pore Size Distributions}

The NMRI measurements have been widely used to evaluate the pore size distributions of porous medias for decades (Yao et al., 
A

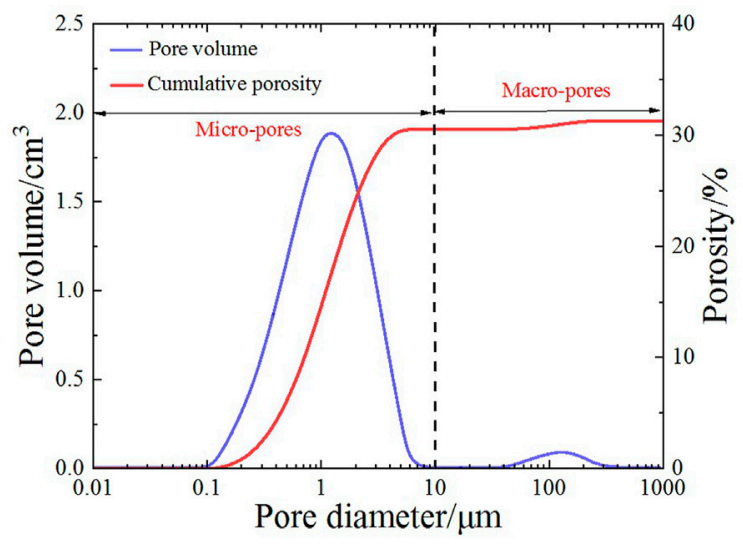

B

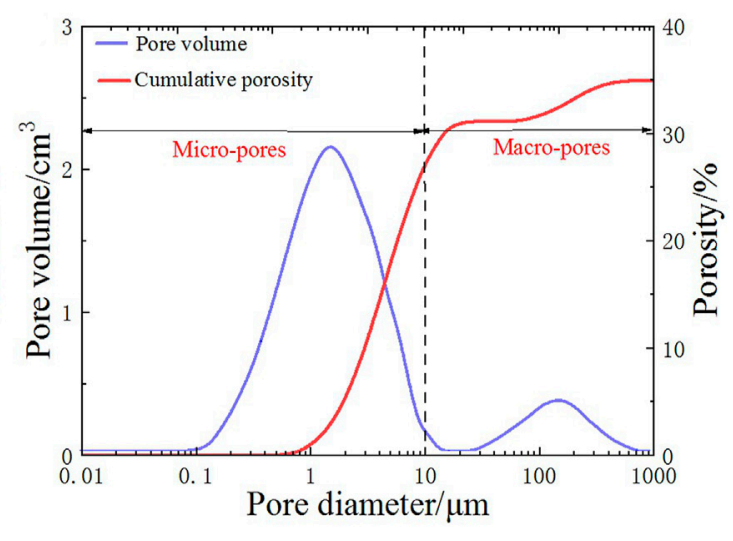

FIGURE 5 | Pore volume distributions of GRS: (A) original specimen, (B) F-T specimen.

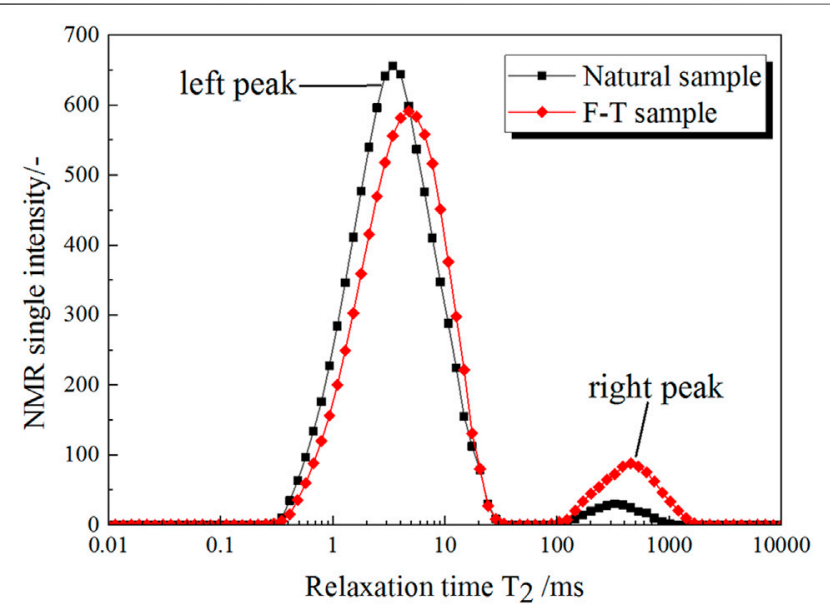

FIGURE $6 \mid T_{2}$ distribution curves from NMR tests.

2021). For the saturated specimens of soils, the porosity is mainly determined by initial moisture contents. It is concluded that the measured $\mathrm{T}_{2}$ distribution curves are used to characterize the pore distributions in soils, where the abscissa is the relaxation time $T_{2}$ representing the pore size and the ordinate is the NMR signal intensity reflecting the pore-water volume with the current size. In this present section, the $T_{2}$ curves of the GRS exhibit two different peaks, as plotted in Figure 6. It is clear that the amplitudes of left peaks are significantly higher than those of right peaks in $\mathrm{T}_{2}$ distribution curves. After the A-T process, the left and right peak in the $T_{2}$ distribution curve of the original specimen both shifted rightward along the X-coordinate, representing a rise in pore diameters of GRS. Moreover, the NMR signal intensity and the spectrum area of the right peak in the $T_{2}$ distribution curve significantly increase under the AGF impact. (ASTMD422-63,2002); ASTMD4926,2015.

The relaxation time $T_{2}$ is complex since it is regulated by three relaxation mechanisms: bulk, surface, and diffusion relaxations.
To simplify, the $T_{2}$ values of porous mediums ascertained from NMRI tests are primarily regulated by the surface relaxation effect, which can be expressed as Eq. 2 (Watanabe and Wake 2009).

$$
\frac{1}{T_{2}}=\rho_{2} \frac{S}{V},
$$

where, $\rho_{2}$ denotes the surface relaxation coefficient, which is a parameter of magnetic interactions at the fluid-solid interface. $\frac{S}{V}$ denotes the ratio of the surface area $S$ to the pore volume $V$.

$$
\frac{S}{V}=\frac{F_{s}}{D}
$$

Where, $F_{\mathrm{s}}$ denotes the geometric factor of pore ( 6 for the spherical pored and 4 for cylindrical pores) and $D$ denotes the pore diameters.

Kong et al. (2017) proved that the cylindrical model is suitable to represent pores in soil, and Eq. 2 can be expressed as:

$$
\frac{1}{T_{2}}=\frac{4 \rho_{2}}{D}
$$

Accordingly, the relaxation time $\mathrm{T}_{2}$ is linearly proportional to the pore diameter. It is viable to estimate the pore diameter by using the $\mathrm{T}_{2}$ distribution curves based on the surface relaxation coefficient $\rho_{2}$. It is worth noting that $\rho_{2}$ is normally assumed to be a constant for a specific sample when interpreting NMR results. The $\rho_{2}$ value depends on the paramagnetic impurities on the grain surfaces interacting with hydrogen nuclei in pore water and the imposing of additional relaxations (Lyu et al., 2018). The $\rho_{2}$ is also related to the combination of pore fluid and mineral grain and pore fluid for interpreting NMR results (Kong et al., 2020). In this study, the $\rho_{2}$ value was determined as $0.258 \mu \mathrm{m} / \mathrm{s}$ based on the Schlumberger-Doll Research (SDR) equation (Daigle and Dugan 2009).

In addition, the pore volume $V_{i}$ of GRS at the current diameter of $D$ is expressed as: 


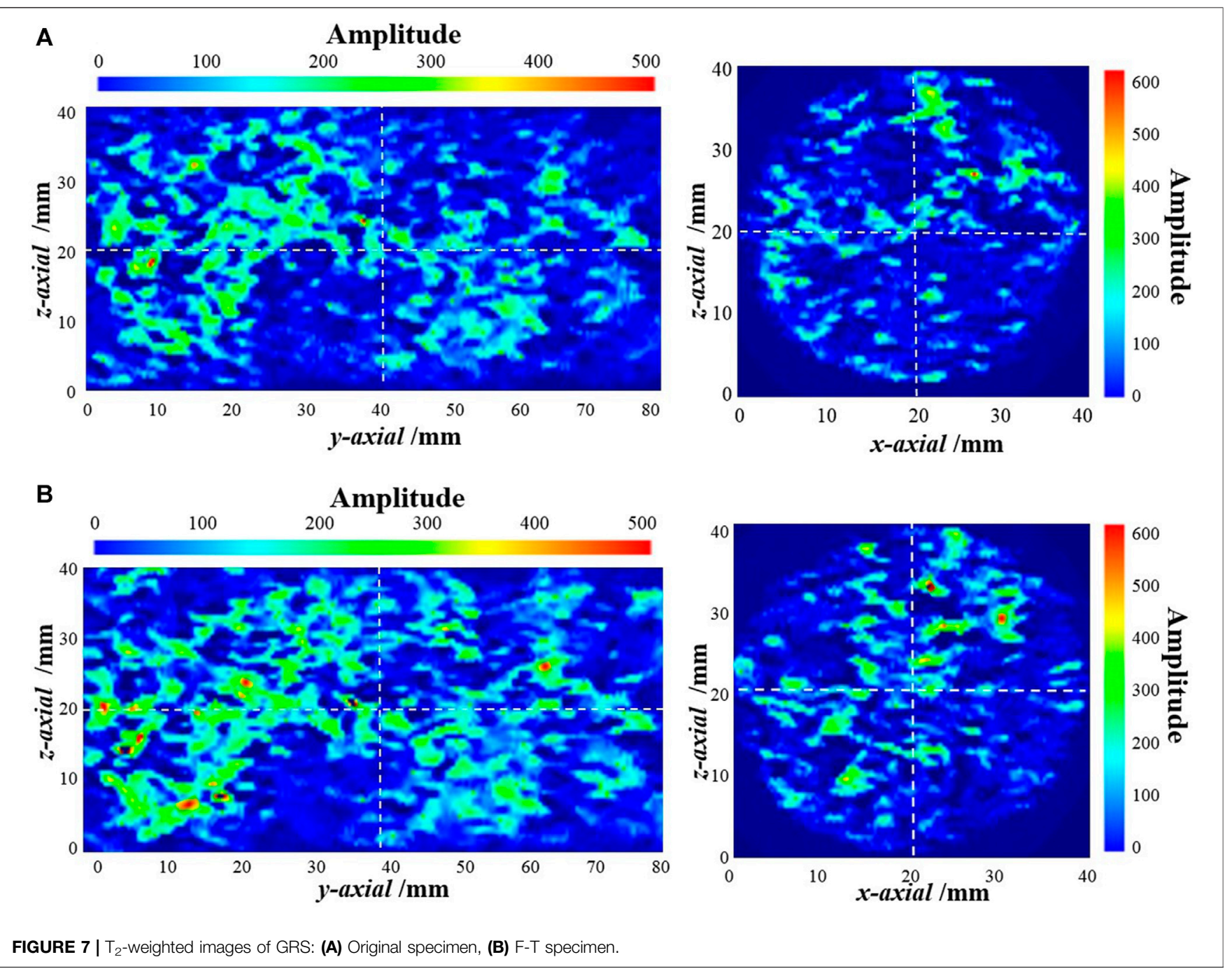

$$
V_{i}=\frac{A_{i}}{\sum A_{i}} \cdot \frac{m_{w}}{\rho_{w}}=\frac{A_{i}}{\sum A_{i}} \cdot \frac{m_{s}-m_{d}}{\rho_{w}},
$$

where $A_{i}$ denotes the amplitude of NMR signal, $m_{w}$ denotes the mass of water, $m_{s}$ denotes total mass of, $m_{d}$ denotes the mass of thoroughly dried specimens, and $\rho_{w}$ is water density.

According to the principle of NMR tests, the volume of pore water in fully saturated samples with different sizes are in fact equal to the corresponding pore volume. Accordingly, the amounts and volumes of pore in the tested samples can be calculated by using the $T_{2}$ spectras and the conversion coefficient $\rho_{2}$ (Kong et al., 2018). Based on the PSD results of original specimens of GRS (see in Figure 5A), the quantified pores that have diameters less than $1 \mu \mathrm{m}$ account for over $40 \%$ of the total pores, while more than $90 \%$ of the pores have a diameter less than $10 \mu \mathrm{m}$. Further, we divided the pores into micro-pores with the equivalent diameter $D<10 \mu \mathrm{m}$ and macro-pores with the equivalent $D>10 \mu \mathrm{m}$. The volumes of pores were calculated considering all pores in the samples, according to the study from Tian et al. (2018). The curves of PSD and cumulative porosity of the GRS after F-T process are given in Figure 5B. The pore size distributions (PSD) of original and F-T specimens are both constituted of two peaks, corresponding to micro-pores with diameters from 0.01 to $10 \mu \mathrm{m}$ and macro-pores with diameters from 10 to $1,000 \mu \mathrm{m}$. After freezing and thawing, the pore volume of the left peak declines while the right peak moves upward, suggesting that the pore size distribution of GRS significantly changed. According to the pore size distribution curves, the macro-pore volume increases sharply, the micro-pore volume decreases slightly, and the total porosity increases by nearly $11.1 \%$, as a result of the AGF impact at the extremely low temperature.

To further analyze the microstructural variations, the pore characteristics of the GRS were obtained based on the imaging features of NMRI tests, as given in Figure 7. The pore water distributed zones in the specimen is visually discerned with $\mathrm{T}_{2^{-}}$ weighted images. In this paper, the $\mathrm{T}_{2}$-weighted profile and crosssectional images were obtained to observe the pore variations of GRS after the F-T process. From Figure 7A, it is obvious that the number of large-scale pores in the original specimen is relatively 
few. The pseudo-color images of GRS after freezing-thawing were presented in Figure $\mathbf{7 B}$, which shows that the AGF impact reinforced the expansion of pores. Besides, the heterogeneous degree of the microstructure is also increased by $\mathrm{F}$-T process, which is proven by the pores in GRS becoming more anisotropic for both profiles and cross-sections. Thus, the change in pore size distributions can be verified from a visualized perspective, according to the results of $\mathrm{T}_{2^{-}}$ weighted images. He et al.,2020.

\section{DISCUSSION}

According to the classical theory of soil mechanics, three components exist in natural soils: the soil skeleton, pore, and water filled in pores (Terzaghi 1943). For granite residual soils in the F-T state, the soil skeleton is composed of coarse and fine particles, the pore is characterized by a binary distribution, and the water exists in solid and liquid forms. The shear strength reduction is attributed to the microstructural disturbance of GRS under the AGF impact. During the freezing-thawing process, the expansive pressures induced by formations of ice lens increase the friability of soil specimens, reducing the off-peak stress in large deformations. Moreover, the thawing procedure of ice lens accumulates the cracking process in GRS, which contributes to the structural failure of the specimen.

When the GRS is at an extremely low temperature, the effect of expansion and shrinkage of soils due to AGF method controls the trend of volume change together (Villar and Lloret 2015). As the distance between soil particles increased, the cohesion force of clay aggregates and sandy particles declined significantly. In addition, the negative pressures in unfrozen areas in the specimens squeezed the clay particles to become more rigid, thereby reducing the decreasing amplitude of the internal friction angle. Accordingly, the frost heaving effect results in an obvious degradation in the cohesion instead of internal friction angle of the specimen. As the freezing front moves, the formation of ice lens in frozen areas and the moisture migration under negative pressures in unfrozen areas both exist, contributing to uneven deformations in the GRS. As a result, the frost heaving and thawing effect causes a disturbance in mechanical behaviors due to AGF constructions (Wang et al., 2020). On this basis, the shear strength decreases synchronously with the pore enlargement of GRS during the AGF process.

\section{CONCLUSION}

Based on this experimental study, the following conclusions are drawn:

\section{REFERENCES}

An, R., Kong, L., Guo, A., and Zhang, X. (2019). A Proposed Method to Determine In-Situ Shear Modulus and Shear Strain Decay Curves in Different Structured Soil. E3s Web Conf. 92 (5), 18004. doi:10.1051/e3sconf/20199218004
1) The process of freezing-thawing on the shear strength of GRS under an extremely low temperature was investigated by performing triaxial loading tests. The stress-strain curves of the original specimen display a strain-softening feature while exhibiting a strain-hardening feature after the F-T process. The cohesion is reduced by about $15.7 \%$ while the internal friction angle was only reduced about $1.5 \%$, due to the AGF impact.

2) Based on the results of NMRI tests, two peaks in the $T_{2}$ distribution curve of the original specimen shift to the right after the AGF process. Meanwhile, the NMR signal intensity of the right peak increases dramatically. With the assistance of the surface relaxation coefficient $\left(\rho_{2}\right)$, the $T_{2}$ distribution curve could be converted to the pore size distribution curve. Under the AGF impact, micropores are squeezed under negative pressures in unfrozen areas and macro-pores are enlarged due to the formation of ice lens.

3) The discussion on frost heaving mechanism demonstrates that the mechanical property is closely related to the pore size distribution. The variation of large pores can be attributed to the formation of ice lens, negative pressures in unfrozen areas, as well as the accumulation of uneven deformations. Therefore, the microstructural disturbance in soil weakened the original cohesive force among grains, directly resulting in a reduction of shear strength. The discussion on pore size distributions primarily interprets the phenomenon of frost heaving damage on mechanical behaviors of GRS under AGF constructions. (Lu et al.,2019; He et al.,2020; Li et al.,2021)

\section{DATA AVAILABILITY STATEMENT}

The raw data supporting the conclusion of this article will be made available by the authors, without undue reservation.

\section{AUTHOR CONTRIBUTIONS}

RA performed the tests and wrote the manuscript. LK designed the tests. XZ processed part of the data. All authors contributed extensively to the review and revision of this manuscript.

\section{FUNDING}

The present study had the financial support of the National Natural Science Foundation of China (Grant Number: 12102312 and 42177148) and Open Fund of State Key Laboratory of Geohazard Prevention and Geoenvironment Protection (Grant Number: SKLGP2021K011).

An, R., Kong, L., and Li, C. (2020). Pore Distribution Characteristics of Thawed Residual Soils in Artificial Frozen-wall Using NMRI and MIP Measurements. Appl. Sci. 10, 544. doi:10.3390/app10020544

An, R., Kong, L. W., and Li, C. S. (2020). Strength Attenuation and Microstructure Damage of Granite Residual Soils under Hot and Rainy Weather. Chin. J. Rock Mech. Eng. 39 (9), 1902-1911. doi:10.13722/j.cnki.jrme.2020.0073 
ASTM D422-63 (2002). Standard Test Method for Consolidated Undrained Triaxial Compression Test for Cohesive Soils. West Conshohocken, PA: ASTM International.

ASTM D4926 (2015). Standard Standard Test Method for Gamma Alumina Content in Catalysts and Catalyst Carriers Containing Silica and Alumina by X-ray Powder Diffraction. West Conshohocken, PA: ASTM International.

Bai, R., Lai, Y., Zhang, M., and Yu, F. (2018). Theory and Application of a Novel Soil Freezing Characteristic Curve. Appl. Therm. Eng. 129, 1106-1114. doi:10.1016/j.applthermaleng.2017.10.121

Black, P. B., and Tice, A. R. (1989). Comparison of Soil Freezing Curve and Soil Water Curve Data for Windsor sandy Loam. Water Resour. Res. 25, 2205-2210. doi:10.1029/wr025i010p02205

Bronfenbrener, L., and Bronfenbrener, R. (2010). Frost Heave and Phase Front Instability in Freezing Soils. Cold Regions Sci. Tech. 64 (1), 19-38. doi:10.1016/ j.coldregions.2010.07.001

Chen, R. P., Li, Z. C., Chen, Y. M., Ou, C. Y., Hu, Q., and Rao, M. (2015). Failure Investigation at a Collapsed Deep Excavation in Very Sensitive Organic Soft clay. Jc Performc Constr. Fac. 2015 (040140783). doi:10.1061/(asce)cf.1943-5509.0000557

Cui, Z.-D., and Zhang, Z.-L. (2015). Comparison of Dynamic Characteristics of the Silty clay before and after Freezing and Thawing under the Subway Vibration Loading. Cold Regions Sci. Tech. 119, 29-36. doi:10.1016/ j.coldregions.2015.07.004

Daigle, H., and Dugan, B. (2009). Extending Nmr Data for Permeability Estimation in fine-grained Sediments. Mar. Pet. Geology. 26 (8), 1419-1427. doi:10.1016/ j.marpetgeo.2009.02.008

Fang, Q., Zhang, D., and Wong, L. N. Y. (2011). Environmental Risk Management for a Cross Interchange Subway Station Construction in china. Tunnelling Underground Space Tech. 26 (6), 750-763. doi:10.1016/j.tust.2011.05.003

Fonseca, A. V. D., Carvalho, J., Ferreira, C., Santos, J. A., Almeida, F., Pereira, E., et al. (2006). Characterization of a Profile of Residual Soil from Granite Combining Geological, Geophysical and Mechanical Testing Techniques. Geotech Geol. Eng. 24 (5), 1307-1348. doi:10.1007/s10706-005-2023-Z

$\mathrm{Fu}$, J., Yang, J., Zhang, X., Klapperich, H., and Abbas, S. M. (2014). Response of the Ground and Adjacent Buildings Due to Tunnelling in Completely Weathered Granitic Soil. Tunnelling Underground Space Tech. 43, 377-388. doi:10.1016/ j.tust.2014.05.022

Han, L., Ye, G.-1., Li, Y.-h., Xia, X.-h., and Wang, J.-h. (2016). In Situ monitoring of Frost Heave Pressure during Cross Passage Construction Using GroundFreezing Method. Can. Geotech. J. 53, 530-539. doi:10.1139/cgj-2014-0486

He, X.-C., Xu, Y.-S., Shen, S.-L., and Zhou, A.-N. (2020). Geological Environment Problems during Metro Shield Tunnelling in Shenzhen, China. Arab. J. Geosci. 13 (2). doi:10.1007/s12517-020-5071-z

He, Z., Xiang, D., and Liu, Y. (2020). Triaxial Creep Test and Particle Flow Simulation of Coarse-Grained Soil Embankment Filler. Front. Earth Sci. 8. doi:10.3389/feart.2020.00062

Kong, L., Sayem, H. M., and Tian, H. (2018). Influence of Drying-Wetting Cycles on Soil-Water Characteristic Curve of Undisturbed Granite Residual Soils and Microstructure Mechanism by Nuclear Magnetic Resonance (NMR) Spin-Spin Relaxation Time (T2) Relaxometry. Can. Geotech. J. 55, 208-216. doi:10.1139/ cgj-2016-0614

Kong, L., Wang, Y., Sun, W., and Qi, J. (2020). Influence of Plasticity on Unfrozen Water Content of Frozen Soils as Determined by Nuclear Magnetic Resonance. Cold Regions Sci. Tech. 172, 102993. doi:10.1016/j.coldregions.2020.102993

Konrad, J.-M., and Morgenstern, N. R. (1980). A Mechanistic Theory of Ice Lens Formation in fine-grained Soils. Can. Geotech. J. 17, 473-486. doi:10.1139/t80-056

Lackner, R., Pichler, C., and Kloiber, A. (2008). Artificial Ground Freezing of Fully Saturated Soil: Viscoelastic Behavior. J. Eng. Mech. 134134, 1-11. doi:10.1061/ (ASCE)0733-939910.1061/(asce)0733-9399(2008)134:1(1)

Li, C., Kong, L., Shu, R., An, R., and Jia, H. (2020). Dynamic ThreeDimensional Imaging and Digital Volume Correlation Analysis to Quantify Shear Bands in grus. Mech. Mater. 151, 103646. doi:10.1016/ j.mechmat.2020.103646

Li, T., Kong, L., and Guo, A. (2021). The Deformation and Microstructure Characteristics of Expansive Soil under Freeze-Thaw Cycles with Loads. Cold Regions Sci. Tech. 192, 103393. doi:10.1016/j.coldregions.2021.103393

Liu, X., Hu, C., Liu, Q., and He, J. (2021). Grout Penetration Process Simulation and Grouting Parameters Analysis in Fractured Rock Mass Using Numerical
Manifold Method. Eng. Anal. Boundary Elem. 123, 93-106. doi:10.1016/ j.enganabound.2020.11.008

Liu, Y., Hu, J., Xiao, H., and Chen, E. J. (2017). Effects of Material and Drilling Uncertainties on Artificial Ground Freezing of CementAdmixed Soils. Can. Geotech. J. 54, 1659-1671. doi:10.1139/cgj-20160707

Lu, Z., Xian, S., Yao, H., Fang, R., and She, J. (2019). Influence of Freeze-Thaw Cycles in the Presence of a Supplementary Water Supply on Mechanical Properties of Compacted Soil. Cold Regions Sci. Tech. 157, 42-52. doi:10.1016/j.coldregions.2018.09.009

Lyu, C., Ning, Z., Wang, Q., and Chen, M. (2018). Application of NMR T2 to Pore Size Distribution and Movable Fluid Distribution in Tight Sandstones. Energy Fuels 32, 1395-1405. doi:10.1021/ acs.energyfuels.7b03431

Nakashima, Y., Mitsuhata, Y., Nishiwaki, J., Kawabe, Y., Utsuzawa, S., and Jinguuji, M. (2011). Non-destructive Analysis of Oil-Contaminated Soil Core Samples by X-ray Computed Tomography and Low-Field Nuclear Magnetic Resonance Relaxometry: a Case Study. Water Air Soil Pollut. 214, 681-698. doi:10.1007/ s11270-010-0473-2

Pellet, C., Hilbich, C., Marmy, A., and Hauck, C. (2016). Soil Moisture Data for the Validation of Permafrost Models Using Direct and Indirect Measurement Approaches at Three alpine Sites. Front. Earth Sci. 3 (91). doi:10.3389/ feart.2015.00091

Pichler, C., Lackner, R., and Mang, H. A. (2003). Continuum-micromechanics Approach for Determination of Frost Heave in Artificial Ground Freezing. Comput. Fluid Solid Mech., 128. 578-581. doi:10.1016/B978-0080440460.50142-1

Pimentel, E., Papakonstantinou, S., and Anagnostou, G. (2012). Numerical Interpretation of Temperature Distributions from Three Ground Freezing Applications in Urban Tunnelling. Tunnelling Underground Space Tech. 28, 57-69. doi:10.1016/j.tust.2011.09.005

Shoop, S. A., and Bigl, S. R. (1997). Moisture Migration during Freeze and Thaw of Unsaturated Soils: Modeling and Large Scale Experiments. Cold Regions Sci. Tech. 25 (1), 33-45. doi:10.1016/s0165-232x(96)00015-8

Terzaghi, K. T. (1943). Theoretical Soil Mechanics. J. Wiley and Sons, inc.

Tian, H., Wei, C., and Tan, L. (2019). Effect of Freezing-Thawing Cycles on the Microstructure of Soils: A Two-Dimensional NMR Relaxation Analysis. Cold Regions Sci. Tech. 158, 106-116. doi:10.1016/j.coldregions.2018.11.014

Toll, D. G., and Ong, B. H. (2015). Critical-state Parameters for an Unsaturated Residual sandy clay. Géotechnique 53 (1), 93-104.

Villar, M. V., and Lloret, A. (2004). Influence of Temperature on the HydroMechanical Behaviour of a Compacted Bentonite. Appl. Clay Sci. 26 (1-4), 337-350. doi:10.1016/j.clay.2003.12.026

Vitel, M., Rouabhi, A., Tijani, M., and Guérin, F. (2015). Modeling Heat Transfer between a Freeze Pipe and the Surrounding Ground during Artificial Ground Freezing Activities. Comput. Geotechnics 63 (jan), 99-111. doi:10.1016/ j.compgeo.2014.08.004

Wang, S., Yang, P., Dai, D., Xue, K., and Li, D. (2020). A Study on Micropore Characteristics of clay Due to Freeze-Thaw and Compression by Mercury Intrusion Porosimetry. Front. Earth Sci. 7, 344. doi:10.3389/ feart.2019.00344

Watanabe, K., and Wake, T. (2009). Measurement of Unfrozen Water Content and Relative Permittivity of Frozen Unsaturated Soil Using NMR and TDR. Cold Regions Sci. Tech. 59, 34-41. doi:10.1016/ j.coldregions.2009.05.011

Yao, C., Wei, C., Ma, T., Chen, P., and Tian, H. (2021). Experimental Investigation on the Influence of Thermochemical Effect on the Pore-Water Status in Expansive Soil. Int. J. Geomech. 21 (6), 04021080. doi:10.1061/(ASCE) GM.1943-5622.0002020

Yuanming, L., Zhihua, G., Shujuan, Z., and Xiaoxiao, C. (2010). StressStrain Relationships and Nonlinear Mohr Strength Criteria of Frozen Sandy Clay. Soils and Foundations 50 (1), 45-53. doi:10.3208/ sandf. 50.45

Zeng, Z., Kong, L., Wang, M., and Sayem, H. M. (2018). Assessment of Engineering Behaviour of an Intensely Weathered Swelling Mudstone under Full Range of Seasonal Variation and the Relationships Among Measured Parameters. Can. Geotech. J. 55, 1837-1849. doi:10.1139/cgj-2017-0582 
Zhang, X. W., Kong, L. W., Yin, S., and Chen, C. (2017). Engineering Geology of Basaltic Residual Soil in Leiqiong, Southern China. Eng. Geology. 220, 196-207. doi:10.1016/j.enggeo.2017.02.002

Zhou, J., and Tang, Y. (2015). Centrifuge Experimental Study of Thaw Settlement Characteristics of Mucky clay after Artificial Ground Freezing. Eng. Geology. 190, 98-108. doi:10.1016/j.enggeo.2015.03.002

Zhou, J., and Tang, Y. (2018). Practical Model of Deformation Prediction in Soft clay after Artificial Ground Freezing under Subway Low-Level Cyclic Loading. Tunnelling Underground Space Tech. 76, 30-42. doi:10.1016/j.tust.2018.03.003

Conflict of Interest: The authors declare that the research was conducted in the absence of any commercial or financial relationships that could be construed as a potential conflict of interest.
Publisher's Note: All claims expressed in this article are solely those of the authors and do not necessarily represent those of their affiliated organizations, or those of the publisher, the editors and the reviewers. Any product that may be evaluated in this article, or claim that may be made by its manufacturer, is not guaranteed or endorsed by the publisher.

Copyright (๑) 2021 An, Zhang, Kong, Gong and Lei. This is an open-access article distributed under the terms of the Creative Commons Attribution License (CC BY).

The use, distribution or reproduction in other forums is permitted, provided the original author(s) and the copyright owner(s) are credited and that the original publication in this journal is cited, in accordance with accepted academic practice. No use, distribution or reproduction is permitted which does not comply with these terms. 